\title{
AN ANALYSIS TO INVESTIGATE SPATIAL COGNITIVE FACTORS WHICH INFLUENCE CYCLING PATTERNS IN JOHANNESBURG
}

\author{
T. Moyo ${ }^{1}$, W. Musakwa ${ }^{2}$, B.T Mokoena ${ }^{3}$ \\ ${ }^{1}$ Dept. of Operations and Quality Management, University of Johannesburg. Cnr Siemert \& Beit Streets, \\ Doornfontein 0184 Johannesburg, South Africa- thembanijoel@gmail.com \\ ${ }^{2}$ Dept. of Town and Regional Planning, University of Johannesburg, Cnr Siemert \& Beit Streets, \\ Doornfontein 0184 Johannesburg, South Africa - wmusakwa@uj.ac.za \\ ${ }^{3}$ Dept. of Town and Regional Planning, University of Johannesburg, Cnr Siemert \& Beit Streets, \\ Doornfontein 0184 Johannesburg, South Africa - balesengmokoena211@gmail.com
}

KEY WORDS: Multi-modal; Cycling; Spatial Cognition; Johannesburg; Smart cities.

\begin{abstract}
:
Cycling in most African cities is done as either a mode of commuting or for recreational purposes. Apart from Smart cities encouraging a shift from cars to public transport by providing efficient last-mile connections, commuter cycling can take a significant share of endto-end short distance trips. The ultimate realization of cycling merits by urban dwellers, (such as in Johannesburg, South Africa) is hindered by a lack of appropriate data to aid in understanding the dynamics of cycling behaviour. This paper seeks to be the first step in building a multi-model to govern the use of multi-modes of mobility in the city by initial focusing on promoting NMT usage as a mode of commuting in the city. Identification of these factors would go a long way in improving cycling uptake as well as inform policy strategies for non-motorized transportation in the city. Using an analytical approach, the authors conducted a survey along preknown locations were cyclist choose to cycle. One route with newly developed cycling infrastructure and another without cycling infrastructure. A self-reported travel behaviour form, was used for the collection of spatial cognitive and attitudinal data on participants' travel environment, attitude, behaviour, norm, intention, and habit was utilized to gather data to understand cyclist cognitive reasoning for choosing one path over another. The data collected from the survey was then overlaid with Strava Metro cycling data showing locations were cyclist prefer to cycle in the city. Findings from the analysis suggest perceived safe routes and routes that maximize health benefits are preferred. Based on the findings it is recommended that planners need to use crowd sourced data before developing infrastructure for cycling the city.
\end{abstract}

\section{INTRODUCTION}

Cycling is booming as a means of transportation owing to its health and economic benefits. Yet, there is limited research assessing factors influencing non-motorized transport users commuting experiences and how they interact with the nonmotorized transportation (NMT) infrastructure within the city of Johannesburg (Rahul \& Verma, 2013). The lack of information, therefore, hinders proper planning for how and where to invest in NMT infrastructure (Lacono at el, 2010). One of the main reasons for such neglect might be that most decision makers have a lack of understanding for the importance of walking and cycling trip distances (Behrens, 2005). Urban planners are often a bit illinformed with regards the distance necessary for development of NMT facilities (Rahul \& Verma, 2013). Given how cycling can play an important role in urban mobility as it is an efficient, nonpolluting and cheap mode for short distance trips. Apart from encouraging a shift from cars to public transport by providing efficient last-mile connections, commuter cycling can take a significant share of end-to-end short distance trips.

Most industrialized cities around the world have over the years been suffering the consequences caused by the over usage of motorized transportation (Jou, 2011). Currently traffic congestion has become the norm in urban centers (Moyo \& Musakwa, 2016), which in turn has adversely affected the economic, as productivity has been reduced due to daily delays on the roads (i.e. people commuting to work or products moving from point A to B) (Kumar, 2014). Given the recent infrastructure developments by the City of Johannesburg to support the expansion of the Bus Rapid Transit (BRT) system and cycling lanes, questions have been raised on whether the city is ready for such smart mobility systems (Jennings, 2011). Currently there has been little research to identify how commuters in the South African context can use multi-mobility modes, as the current mobility system is not spatially integrated. Hence presenting a need for a creation of a new model which will address knowledge gaps on how to improve and promote multi-modes of mobility in urban space. This paper seeks to be the first step in building a multi-mobility model to govern the use of multi-modes of mobility in the city by initial focusing on promoting NMT usage as a mode for daily commuting in the city.

\subsection{Literature Review}

Much has been said about how adopting non-motorized mobility can lead to reduced transportation problems. Studies ranges from investigation of factors which influence how cyclist interpret/react to their physical environment to how services have been introduced to enhance the cycling experience. That is, the connectivity levels between the various points of interest of the cyclist, this would lead to variations in pull and push factors in deciding the route to be taken for any trip. Hence leading to variations in spatial cognition interpretation by different cyclists.

In understanding cyclist route choice Broach et al., (2012) proposed the analysis of global positioning (GPS) data. In their research they suggested using a sample of consistent cyclists to improve validate of the results. Given that the participants commute on a regular basis, their results reveal that most trips made from home to work direction were covered with greater time pressure to be completed. This shows how each regular 
cyclist with time will become aware of the differences in pull and push factors influencing trip's route choice and time given for completion.

To a great extent historical experiences play a major role in spatial cognition as this improves travel appeal. Through empirical research, scholars such as Poslad (2015) have articulated how urban transportation should not only be viewed as an efficient and manageable system for the city authorities but it should meet the needs and wants of the end user that is the commuter. Through research into the spatial cognition of the cyclist, this can inform city authorities were to develop cycling infrastructure. As involving the cyclist in the planning process will unveil insight on where there is a demand to develop infrastructure for cycling.

Yeboah et al., (2015) conducted a study to provide evidence on the utilization of cycling infrastructure. Using GPS-tracked data they matched the route used by cyclist and overlaid this data with spatial datasets of cycling infrastructure, they were able to compare route choice preferences of the participants. Finding from the analyses reveal that $57 \%$ trips occur where there is cycling infrastructure and $43 \%$ were they is no cycling infrastructure. Given the emerging importance of non-motorized transportation there is hence need for more research into identifying factors which lead to such a high number of cyclists preferring to cycle where there is little cycling infrastructure.

Another emerging area is the promotion of bicycle sharing services (BSS) which are rapidly growing globally. Gua \& Liu (2012: 578) define BSS as "a number of bicycles are made available for shared use by individuals who do not own the bicycles." As one of the essential components of the Public Transport Strategy (PTS) is to 'develop adequate infrastructure for NMT modes feeder services and the densification along corridors' (Struwig \& Anderson, 2013). Given how bicycle riding has many benefits (ranging from less road congestion and keeping the rider fit), BSS have been well received such as in China were Hangzhou has bicycle sharing stations every 100 metres (Gua \& Liu, 2012). Currently most research being undertaken on BSS is aimed at improving end user experience through developments of mobile applications. Rani \& Vyas (2017) proposed a new means to enhance the efficiency of BSS by making bicycles smart by deploying sensors on bicycles which helps in collecting real-time data and to forward them to nearby stations. They also developed a framework to map how the user books a bicycle through sensors embedded on the bicycles.

Meanwhile other scholars focus on improving safety on BSS. Basch et al., (2014) conducted a survey to determine how often riders of the New York Citi Bike use helmets on their trips. Their results reveal commuting trips recorded a higher percentage of riders who wear helmets than trips under taken for recreational purposes. With regard to South Africa, Selala \& Musakwa (2016) have revealed that for the city of Johannesburg most cycling trips which occur are undertaken for recreational purposes. Hence if the trend observed by Basch et al., (2014) is also true in Johannesburg, there is a need for research to understand rider's cognitive interpretation of safety whilst cycling in the city.

Within the South African context, much emphasis has been placed on the financial implications of the devolution of traditional transportation facilities. Due the nature of urban centres, De Beer \& Valjarevic (2015) conducted a study to analyse factors influencing cyclists in Johannesburg. Their results reveal topography, operational models, and cycling infrastructure as the common factors for various age groups. This presents a starting point for the introduction of BSS in Johannesburg from the city authorise perspective. Other key issues to be addressed will be a needed for integration of the urban space and improving connectivity levels amongst the various public transportation infrastructure. However, it is clear that there is much work that needs to be done in order to better understand how mobility in Johannesburg can become more sustainable and effective in providing improved levels of access and mobility to a wider spectrum of people.

\subsection{Urban Mobility in South Africa}

South Africa needs to migrate from the use of private motor cars towards more sustainable modes of transport in order to address the recent transport crisis (Mammon et al., 2008). For this reason, the use of non-motorized transport was introduced as a means to reduce the use of motorized transportation (Mammon et al., 2008). Cycling in South Africa is seen primarily as two distinctions; it is either seen as a sport by the effluent class or a mode of transport for low-income households (who usually cannot afford private cars and public transport fares) (Gwala, 2007). The current analysis on transportation patterns indicates that focus is mainly on prioritizing the private vehicle with large resources invested in 'roadways for movement', instead of promoting public and non-motorized transport (Dewar \& Todeschini, 2004; Moyo \& Musakwa, 2017).

Evidence to this is the inadequate information existing on the use of non-motorized transport, trip data and quantitative accident data (CoCT, 2003). There is less accommodation on the roads for pedestrians and cyclists, some the roads are too wide, and it makes it difficult to cross and turns at intersections are also not pedestrian friendly (Mohan, 2002). Surveys/researches that look beyond motorized peak hours and travelling surveys of commuters are very limited and these result in lack of awareness and understanding on the importance of cycling and walking as modes of transport in South African cities (Behrens, 2005). In most instances, data collection on travelling patterns were focused on trips made using motorized transportation and mostly just during peak hours (Behrens, 2004). As a result, not much information is available regarding non-motorized transport user's movement patterns.

Selala \& Musakwa (2016) conducted a survey to unpack the potential of using Strava data to map cycling patterns in the city of Johannesburg. The data collected consisted of cycling trips and attributes divided into recreational and commuting trips. Their results reveal a discernible pattern, as most recreational and commuting trips occurred between $4 \mathrm{am}$ to $9 \mathrm{am}$ and increased again in the evening between $3 \mathrm{pm}$ to $5 \mathrm{pm}$. Also, it is notable that most cycling trips within the city were observed in residential areas at the northern parts of the city, with little to no cycling being observed within the city's central business district. This is greatly concerning as the city recently introduced cycling infrastructure within the CBD. Perhaps there is need for more research into spatial cognition, to determine driving factors which push or pull cyclist route choice. As only using Strava data only may not enough to visualising cycling patterns.

The public bicycle system was introduced in the city of Cape Town (Struwig \& Anderson, 2013). This system has recently received increased attention in the city (Struwig \& Anderson, 2013). The provision of infrastructure for non-motorized transport has been perceived as an interesting and acceptable solution to traffic congestion that needs to be seriously 
considered (Mbara \& Celliers, 2013). Some intervention strategies to promote and support cycling were suggested, such strategies include the provision and maintenance of adequate pedestrian infrastructure and the integration of NMT and PT (Martens, 2004). Theoretically, this was supposed to encourage cycling within the city since people did not have to buy their own bicycle (Jennings, 2014). Unfortunately, motorist behaviour is making it a bit difficult for cyclists to benefit from such interventions. There have been incidences where car drivers use the green lanes for parking, were trucks use the lanes for offloads, minibus taxis using the lanes to overtake, to offload and to pick up passengers (JUCA, 2016).

For short distance, trips completed by student/learners and trips that are highly convenient for NMT in Johannesburg, the most preferred and appropriate modes of transport to use are either cycling or walking (City of Johannesburg, 2009). The international standard distance for walking ranges between 500 $\mathrm{m}$ to $1 \mathrm{~km}$ (Rahul \& Verma, 2013). The reasonable travel times recommended for NMTs are 30 minutes for trips to jobs or schools and 10 to 15 minutes for shopping trips and trips to access other services (Behrens, 2003). The recommended destinations are within a maximum of $10 \mathrm{~km}$ for cycling (City of Johannesburg, 2009). Since most trips in Johannesburg are longer, the utilization of multiple modes of transportation seems a variable option for daily commuter with NMT being used for the first or last portion of the trip and public transportation utilized for the middle portion.

The city of Johannesburg has identified the movement patterns of access to the major taxi ranks, Metrorail, Rea Vaya and Gautrain stations to invest into by upgrading road facilities such as pavements, signage and lighting in these locations (Chakwizira, 2007). More actions that could be done to improve NMT by the city would be implementing the NMT projects concentrating on interlinking land uses with existing universities and schools facilities (Balsas, 2003). Given that it is not established as part of the culture in Johannesburg to make trips using cycling, it is suggested that it will be easier to currently focus just on learners as a start to changing such mentality (City of Johannesburg, 2009; Selala \& Musakwa, 2016).

\section{METHODOLOGY}

A focus on NMT in the study was done to assess how far people have shifted from using motorised transport to environmentally friendly alternatives. Also how sustainable is using cycling as a form of smart mobility to enrich the overall commuting experience. Using an analytical approach, the authors conducted a survey along pre-known locations were cyclist choose to cycle. One route with newly developed cycling infrastructure from the University of Johannesburg Doornfontein (DFC) campus to the University of Witwatersrand (see figure 1) and another without cycling infrastructure from the University of Johannesburg Auckland Park (APK) campus to Emmarentia dam (see figure 2).

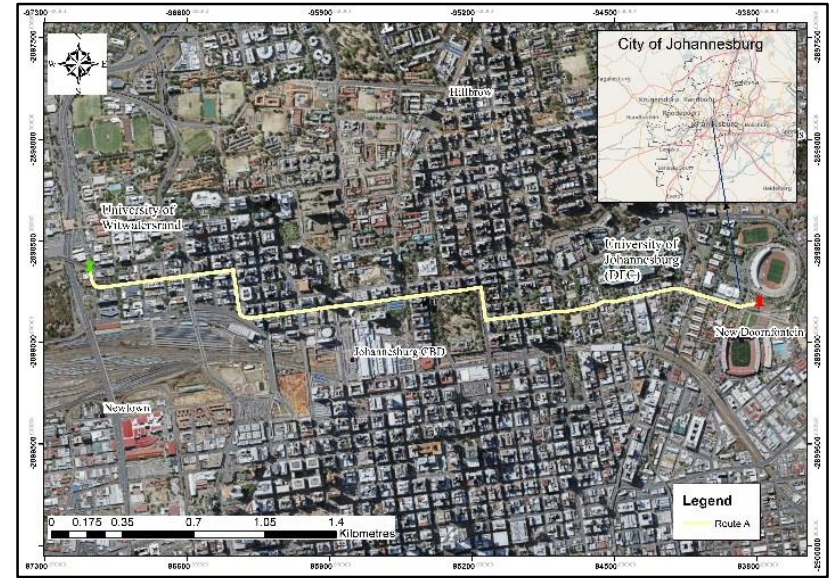

Figure 1: Route A

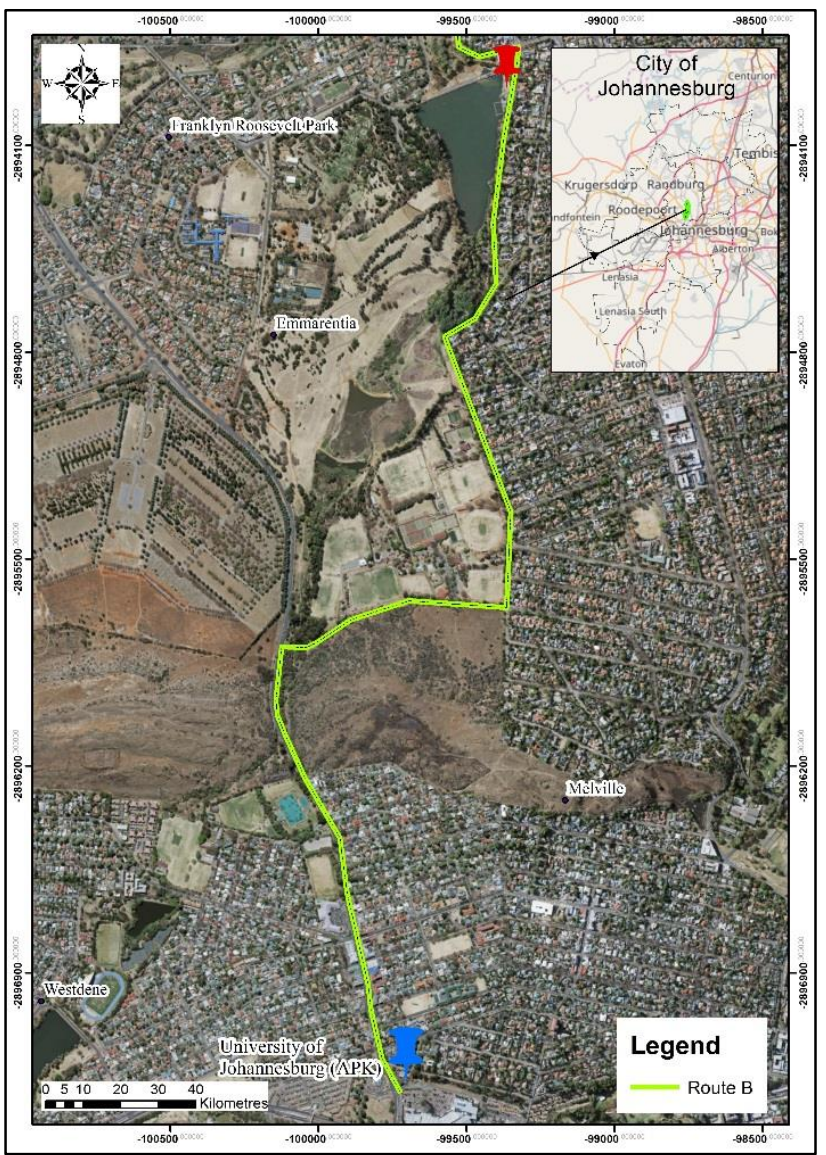

Figure 2: Route B

A self-reported travel behaviour form/questionnaire, was used for the collection of spatial cognitive and attitudinal data on participants' travel environment, attitude, behaviour, norm, intention, and habits. The responses were used to understand cyclist cognitive reasoning for choosing one path over another. Using purposive sampling to target community members who either reside or frequent the site locations (that is within a 1 mile of the chosen routes), the questionnaire was distributed through google forms and social media platforms namely Facebook, Twitter and Google Plus. The data collected from the survey was then overlaid with Strava Metro cycling data for the year 2014 (Musakwa \& Selala, 2016) to visualise trends between the two data sets. 
82 participants filled in the questionnaire, but only 56 were regular cyclists. Using a correlational analysis and descriptive statistics the perception of cyclists were gleaned. Table 1 shows a summary of the factors identified for the study which were grouped into 4. It is noteworthy to highlight how this study is limited in that the research objective was to understand cyclist cognitive interpretation of their environment based on the riders' views and observations along the two routes. Without directly surveying each rider's individual trips, we cannot spatially visualize all the cycling trips. However, the results promise to bring insight on how the riders plan their cycling trips.

Table 1. Factors influencing cycling trips in Johannesburg.

\begin{tabular}{ll}
\hline Theme & Factor \\
\hline Physical & Road width \\
Characteristics & Condition of cycle lane \\
& Existence of cycling infrastructure \\
& Slope gradient \\
Perception of safety & Level of traffic volume \\
& Speed of traffic on route \\
& Sharing road with other forms of mobility
\end{tabular}

$\begin{array}{ll}\text { Route choice } & \begin{array}{l}\text { Location of points of interest } \\ \text { Total trip length } \\ \text { Total trip duration }\end{array} \\ \text { Availability of } & \begin{array}{l}\text { Location of Bicycle sharing services } \\ \text { Multiple modes of mobility }\end{array}\end{array}$

\section{RESULTS AND DISCUSSIONS}

The capabilities of exploring cognitive data have greatly be explored in research. The results indicate that more males' cycle as opposed to women preference to cycle regularly, and this is reflective of cultural bias. Similarly, respondents aged between 19-35 cycles more frequently (Table 2). Most cycling was done in the morning and $42 \%$ of the respondents indicated that they cycle daily. Overall there appears to be an increased uptake of cycling activities amongst the respondents, hence more should be done in promoting cycling as a mode of transport in Johannesburg.

Table 2. Cycling demographics and patterns.

\begin{tabular}{llll}
\hline Gender & Age & Cycling frequency & Travel times \\
\hline Male: 67\% & Less than 18 years: 18\% & Daily: 42\% & Early morning: 44\% \\
Female: 33\% & 19 to 25 years: 42\% & A few times a week: 28\% & Mid-morning: 32\% \\
& 26 to 35 years: 32\% & A few days a month: 24\% & Noon: 0\% \\
& 35 to 50 years: 6\% & Once in a while:4 $\%$ & Afternoon: 16\% \\
& Above 50 years: $2 \%$ & Never: 2\% & Evening: $8 \%$ \\
\hline
\end{tabular}

\subsection{Factors Influencing cycling}

Conditions of cycling lanes and the slope of the route have a huge bearing in determining when and where cycling occurs in Johannesburg (Figure 3). 80\% of the responses received reveal severely steep areas are avoided, with most non-experienced cyclist preferring flat surfaces. However, it is noteworthy that the respondents did not clearly define which slope gradient is regarded as being severely steep. Slope is relevant for recreational cyclist who want to maximize exercises and health benefits by selecting steeper routes whereas commuters normally prefer gentle to flat routes. The state of the cycle lanes as well as the existence of cycling infrastructure are also the second most determining factor for cyclists. However only $30 \%$ of riders considered these as important in trip preparation.

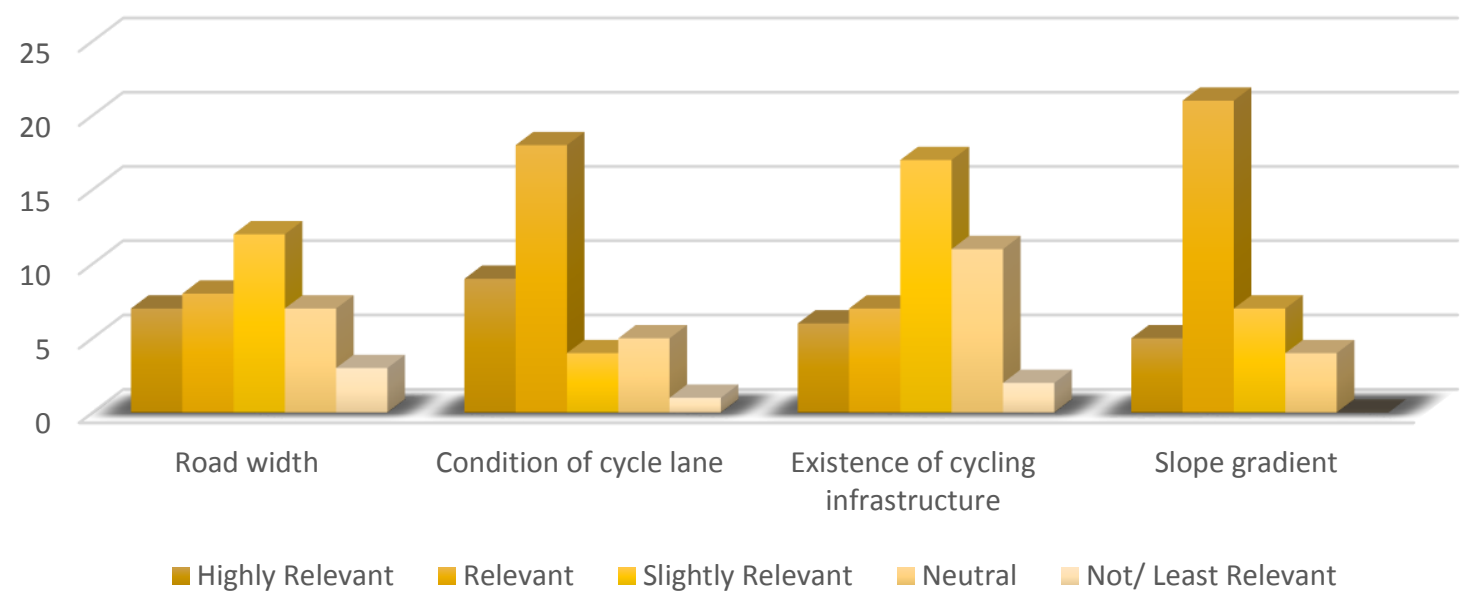

Figure 3: Impact of physical attributes and infrastructure on cycling in Johannesburg

Cyclist safety is of great concern to city authorities (Dewar \& Todeschini, 2004; City of Johannesburg, 2009; Selala \& Musakwa, 2016). Nonetheless, the result of this survey reveals that only $18 \%$ of the cyclists were anxious about their personal safety while cycling, as most do not always were helmets (Figure 4). However, with regards to awareness of other forms of mobility on the road, most reported a high concern regarding their safety. 
With regards to the level of traffic volumes and sharing the road having $82 \%$ and $76 \%$ respectively as most cyclist preferred routes with little traffic hence these were marked as highly relevant in trip planning. $62 \%$ reported being anxious about travelling on roads with high speeding traffic. This is typical of automobile road users (namely mini-bus drivers) in South Africa who often disregard road users leading to a high rate of accidents with cyclist as well as conflicts. Cyclists opted for longer routes to avoid motor vehicle traffic so as to minimize accidents and contact with other traffic modes.

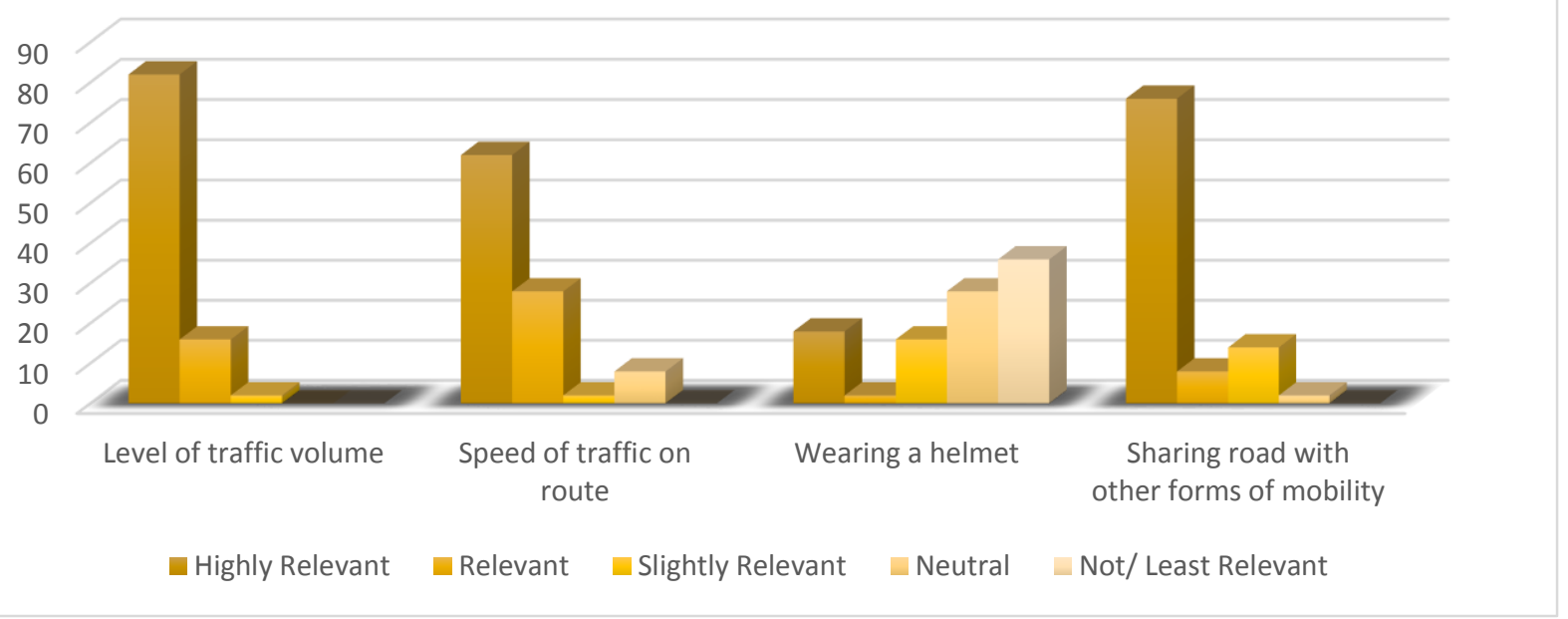

Figure 4: Perception of cyclist's safety in Johannesburg

One of the factors considered to be of prime importance in the choice of routes is the existence of points of interests along the route. $50 \%$ of the participants prefer routes which pass along points of interest, while $16 \%$ do not choose routes along these and the remaining $34 \%$ being indifferent (Figure 3 ). These points of interest include parks, shopping areas, offices, and educational institutions. Hence points of interest such as parks are hotspots for cycling.

To a great extent there seems to be a relationship with regards to trip length and trip duration, with $72 \%$ and $68 \%$ recording these as key factors in trip planning. It appears that most cycling trips are undertaken within the shortest possible time with the aim to reduce total distance travel as the end goal. Hence this bringing insight on how to improve areas which are currently not being directly serviced by the existing cycling infrastructure, they should meet the cyclist need of efficiency with regards to travelling time and distance coverage (i.e. creation of many alternatives routes).

\subsection{Visualisation of Cycling in Johannesburg}

Using cycling data collected from Strava Metro, the authors overlaid this data with the locations the respondents preferred to cycle at. There seems to be correspondence between the locations of commuting trips and most of the points of interest revealed by the respondents, as on Route B, average of 700 to 8000 cycling trips were recorded in 2014 (see figure 5). This high frequency could be due to recreational cycling trips made near the There are several reasons behind this trend such as the reduced traffic volumes at these locations, the steepness of the slope. Route A had average of 0 to 2000 cycling trips in 2014 (see figure 6). This lower frequency in cycling trips could be due the high traffic volumes within the inner city. Based on the identified criteria of factors influencing cycling planners and city authorities should upgrade the existing infrastructure at locations such as Route B to promote cycling.

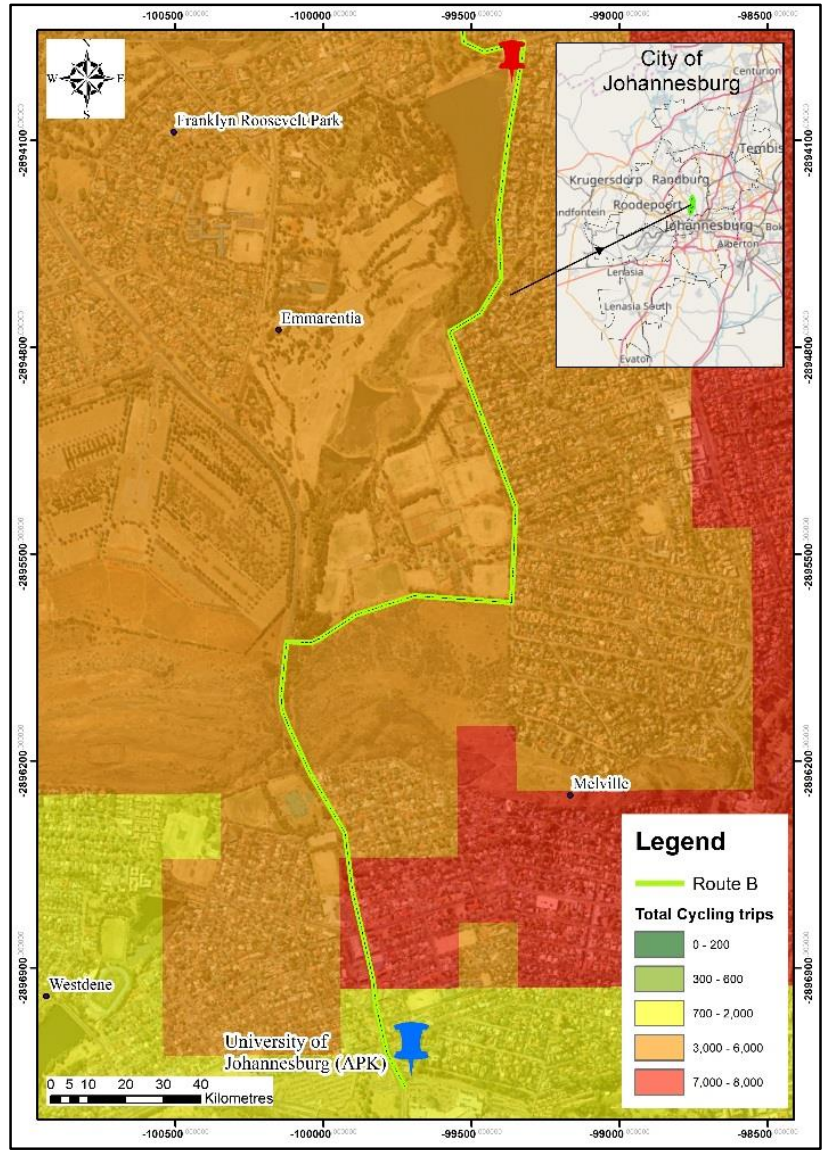

Figure 5: Route B overlaid with Total cycling trips recorded on Strava Metro 


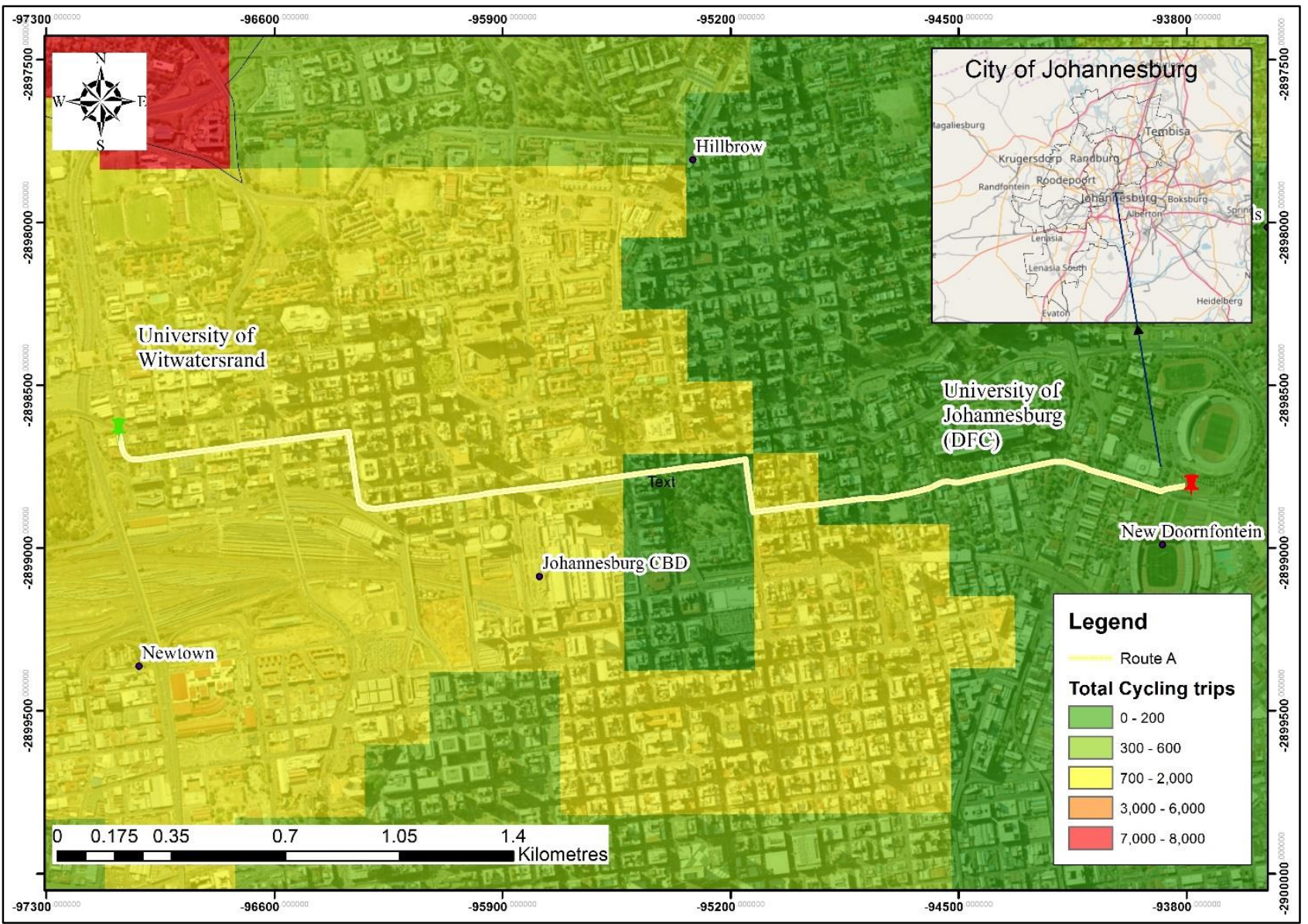

Figure 6: Route A overlaid with Total cycling trips recorded on Strava Metro

\section{CONCLUSION}

To conclude, the aim of the paper was to determine the spatial cognitive factors influencing cycling in Johannesburg. The analysis on the relationship between safety and cycling indicates the safety concerns might not have that much impact on the levels of cycling within Johannesburg as assumed as most cyclist do not always wear helmets. Whereas the physical characteristics of environment seem to have higher impact on the cycling levels. The use of proximity as a criteria to prioritize areas when providing NMT infrastructure seems greatly inter-linked with the riders' points of interest. This gives an impression that more cycling infrastructure should be placed near these points of interest. However, it is noteworthy that recreational trips do not always follow this trend, as cyclist may wish to explore new routes.

Currently developments in NMT are hindered by the lack of information, therefore, hinders proper planning for how and where to invest in NMT infrastructure. Policy-makers and stakeholders can make NMT decisions based on the results of the spatial cognitive survey, as deep analysis into factors which influence cycling routes can lead to better forward planning.

\section{REFERENCES}

Balsas, C.J., 2003. Sustainable transportation planning on college campuses. Transport Policy, 10(1), pp.35-49.

Basch, C.H., Ethan, D., Zybert, P., Afzaal, S., Spillane, M. and Basch, C.E., 2015. Public bike sharing in New York City: helmet use behavior patterns at $25 \mathrm{Citi}^{\mathrm{Bike}} \mathrm{TM}^{\mathrm{TM}}$ stations. Journal of community health, 40(3), pp.530-533.

Behrens, R., 2005. Accommodating walking as a travel mode in South African cities: Towards improved neighbourhood movement network design practices. Planning Practice \& Research, 20(2), pp.163-182.

Broach, J., Dill, J. and Gliebe, J., 2012. Where do cyclists ride? A route choice model developed with revealed preference GPS data. Transportation Research Part A: Policy and Practice, 46(10), pp.1730-1740.

Chakwizira, J., 2007. Question of road traffic congestion and decongestion in the Greater Johannesburg area: some perspectives. Conference Planners.

City of Cape Town., 2003. MSDF Review - Phase 1: Spatial Analysis, Trends and Implications. Draft Report April/May 2003. Prepared for the Spatial Planning and Environment: Development Services Branch.

City of Johannesburg, 2009. Framework for non-motorised transport, January 2009.

Dewar, D. and Todeschini, F., 2017. Rethinking urban transport after modernism: lessons from South Africa. Routledge.

Guo, A. and Liu, G., 2012. A design of bike sharing system based on GPS. In Advances in Mechanical and Electronic Engineering (pp. 587-592). Springer, Berlin, Heidelberg. 
Gwala, S., 2007, July. Urban Non-Motorised Transport (NMT): A Critical Look at the Development of Urban NMT Policy and Planning Mechanisms in South Africa. In Proceedings of the 26th Southern African Transport Conference (SATC 2007)(Vol. 9, p. 12).

Jennings, G., 2015. Finding our balance: Considering the opportunities for public bicycle systems in Cape Town, South Africa. Research in Transportation Business \& Management, 15, pp.6-14.

Johannesburg urban cyclist association, 2016.

Jou, K.K., 2011. Pedestrian areas and sustainable development. World Academy of Science, Engineering and Technology, 5, pp.5-21.

Kumar, A., Nguyen, V.A. and Teo, K.M., 2016. Commuter cycling policy in Singapore: a farecard data analytics based approach. Annals of Operations Research, 236(1), pp.57-73.

Iacono, M., Krizek, K.J. and El-Geneidy, A., 2010. Measuring non-motorized accessibility: issues, alternatives, and execution. Journal of Transport Geography, 18(1), pp.133-140.

Mammon, N., Ewing, K. and Paterson, J., 2008. Urban Challenges of Inclusive Cities-towards a spatial realm for all. Report prepared for the Urban Development Component of a Second Economy Strategy for the Office of the Presidency. Cape Town: NM \& Associates Planners and Designers.

Martens, K., 2004. The bicycle as a feedering mode: experiences from three European countries. Transportation Research Part D: Transport and Environment, 9(4), pp.281-294.

Mbara, T.C. and Celliers, C., 2013. Travel patterns and challenges experienced by University of Johannesburg offcampus students. Journal of Transport and Supply Chain Management, 7(1), pp.1-8.

Mohan, D., 2002. Traffic safety and health in Indian cities. Journal of Transport and Infrastructure, 9(1), pp.79-94.

Moyo, T. and Musakwa, W., 2017. The potential of social media to demarcate the catchment of commuters of the Gautrain public transit system.

Moyo, T. and Musakwa, W., 2016. Using crowdsourced data (Twitter \& Facebook) to delineate the origin and destination of commuters of the Gautrain public transit system in South Africa. ISPRS Annals of the Photogrammetry, Remote Sensing and Spatial Information Sciences, 3, p.143.

Poslad, S., Ma, A., Wang, Z. and Mei, H., 2015. Using a smart city IoT to incentivise and target shifts in mobility behaviourIs it a piece of pie?. Sensors, 15(6), pp.13069-13096.

Rahul, T.M. and Verma, A., 2013. Economic impact of nonmotorized transportation in Indian cities. Research in transportation economics, 38(1), pp.22-34.

Rani, M. and Vyas, O.P., 2017. Smart Bike Sharing System to Make the City Even Smarter. In Advances in Computer and Computational Sciences (pp. 43-55). Springer, Singapore.
Musakwa, W. and Selala, K.M., 2016. Mapping cycling patterns and trends using Strava Metro data in the city of Johannesburg, South Africa. Data in brief, 9, pp.898-905.

Struwig, C.B. and Andersen, S.J., 2013, October. Challenges in providing integrated traveler information in a developing country environment. In Intelligent Transportation Systems-(ITSC), 2013 16th International IEEE Conference on (pp. 750-755). IEEE. 